\title{
Numerical analysis of axial compressive behavior of RC short columns subjected to non-uniform fire: A meso-scale study
}

\author{
Xiaoya $\mathrm{Li}^{1}$, Renbo Zhang ${ }^{1}$, Liu $\mathrm{Jin}^{1 *}$ and Xiuli $\mathrm{Du}^{1}$ \\ ${ }^{1}$ Key Laboratory of Urban Security and Disaster Engineering of Ministry of Education, Beijing University of Technology, Beijing, 100 \\ Pingleyuan, Chaoyang District, China
}

\begin{abstract}
The bearing capacity and durability of reinforced concrete (RC) structures can be affected by fire. In this study, a three-dimensional (3D) meso-scale simulation model for RC short column subjected to axial compression after exposure to fire was established. The degradation effect of mechanical properties of steel bars and concrete materials after high temperature was taken into account. The bond-slip behavior between longitudinal steel bars and concrete was also considered in the model. Based on the present simulation method, the failure mode and failure mechanism of the RC short columns were investigated. Moreover, the effects of fire scenario and fire duration on the axial compression performance of $\mathrm{RC}$ short columns were further investigated. It is found that the meso-scale numerical model can effectively simulate the mechanical behavior of RC short columns under axial load. Moreover, with the increase of fired surfaces and fire duration, the peak bearing capacity, axial compression stiffness and ductility decrease. The mechanical properties of short columns decrease more quickly under non-uniform fire. By comparing the theoretical value with the numerical simulation value of $N_{\mathrm{u}} / N_{\mathrm{u}}$, it is found that the theoretical value is conservative.
\end{abstract}

\section{Introduction}

As the main load-bearing components, reinforced concrete (RC) columns may experience local or even overall damage due to the high temperature, thus losing a portion of its bearing capacity and affecting the service life of buildings. It is of great engineering significance to study the mechanical behavior evolution and damage mechanism of RC columns after elevated temperature.

Abdulraheem and Kadhum [1] found that the initial stiffness and secant stiffness of the columns decreased significantly through the experiments. Martins and Rodrigues [2] found that the fire resistance of columns increased with the cross-section dimensions by experiments. The experimental results of Huo et al. [3] have indicated that with the increase of temperature, the axial compression stiffness and ductility coefficient of columns decreased continuously. In addition, the influence of load, section size, concrete strength and other parameters on the fire resistance of $\mathrm{RC}$ columns were analyzed by numerical model $[4,5]$. On the basis of some assumptions, Nguyen et al. [6] developed a simplified theoretical analysis model for calculating temperature induced restraint force.

It can be seen through the abovementioned work, a lot of efforts have been devoted and promoted to the understanding of the failure mode and damage mechanism of RC columns under the action of fire or high temperature. However, there are still some issues left open to be studied and discussed. For example, most of the physical tests set the fire scenarios as uniform fire on four sides. The available numerical models are usually macroscopic models, which cannot reveal the failure mechanism of components in depth. Moreover, the interaction between steel bars and concrete is always supposed as perfect bond, neglecting the relative slip between them [4]. Therefore, in this study, a three-dimensional (3D) meso-scale finite element (FE) numerical models for RC short column considering bond-slip behavior were established to investigate the axial compression behavior after exposure to fire.

\section{Mesoscopic model for RC short columns}

\subsection{Geometric model}

From a viewpoint of meso-scale, the concrete was considered as a heterogeneous three-phase material consisting of aggregate, mortar matrix and interface transition zone (ITZs) connected the former two phases [7]. The 3D numerical model and rebar arrangement of RC short column can be seen in figure 1. Moreover, the "concrete-steel bond-link element" proposed in [8] was used to describe the nonlinear bond-slip behavior between longitudinal reinforcement and concrete.

*Corresponding author Email: jinliu@bjut.edu.cn 
(a)

Axial loads $N$

Plate

Mortar matrix

Aggregate

ITZ

Longitudinal rebar

Stirrups

(b)
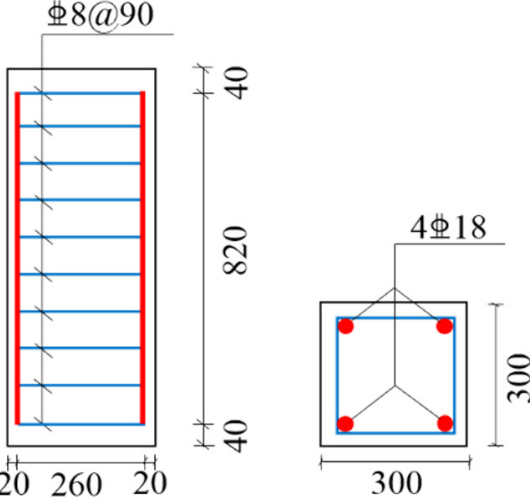

Figure 1. Numerical model of the RC short column. (a) Loading mode; (b) Cross-section size and rebar arrangement.

\subsection{Constitutive model and parameters}

2.2.1 Heat transfer analysis. The influence of temperature on thermal parameters of concrete is considered in the present work [9], as shown in figure 2 . The thermal parameters of concrete at room temperature were listed in Table 1 [10-12]. The density, thermal conductivity and specific heat of steel bar was regarded as constant value of $7850 \mathrm{~kg} / \mathrm{m}^{3}, 45 \mathrm{~W} /\left(\mathrm{m}^{\circ}{ }^{\circ} \mathrm{C}\right)$ and 600 $\mathrm{J} /\left(\mathrm{kg} \cdot{ }^{\circ} \mathrm{C}\right)$, respectively [13].

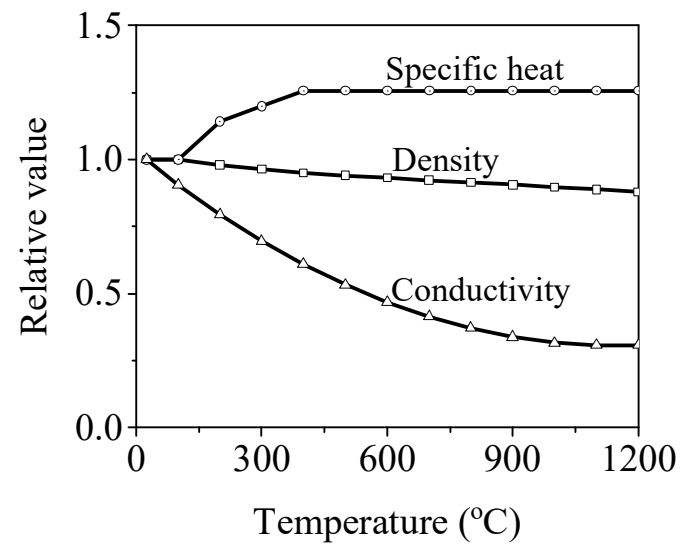

Figure 2. Evolution of density, thermal conductivity and specific heat capacity for concrete with temperature.

Table1. Thermal parameters for the concrete components at room temperature.

\begin{tabular}{llll}
\hline Material parameters & Aggregate & Mortar matrix & ITZ \\
\hline Heat conductivity $k[\mathrm{~W} /(\mathrm{m} \cdot \mathrm{K})]$ & $3.15[10]$ & $1.9[10]$ & 0.7 \\
Special heat capacity $c[\mathrm{~J} /(\mathrm{kg} \cdot \mathrm{K})]$ & $798[11]$ & $813[12]$ & 906 \\
Mass density $\rho\left[\mathrm{kg} / \mathrm{m}^{3}\right]$ & 2750 & 2400 & 2200 \\
\hline
\end{tabular}

\subsubsection{Constitutive model and mechanical parameters} The mortar matrix and the ITZs were described by the damage plastic model [14]. The aggregate phase was assumed to be elastic [15]. The bilinear elastoplastic model was used to describe the mechanical behavior of

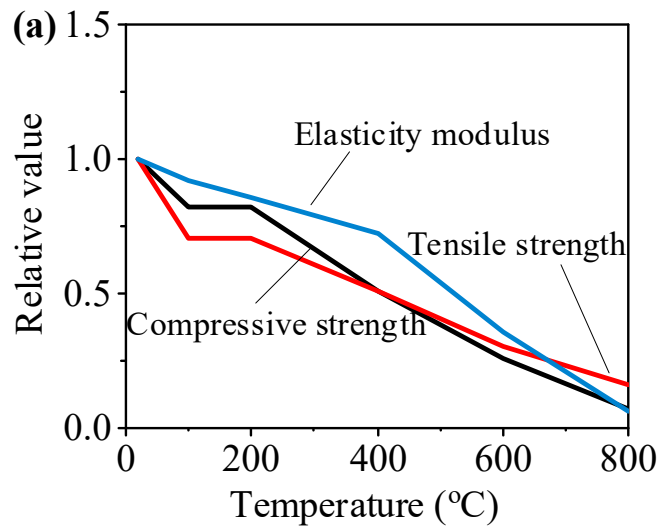

steel bars. The bond stress-slip relationship between concrete and steel bars was used to describe their interaction behavior [16]. In this work, the mechanical performance degradation rule established by Ref. [17-19] for concrete and rebar after high temperature was used, as plotted in figure 3 . The mechanical parameters of different components at room temperature are listed in Table 2.

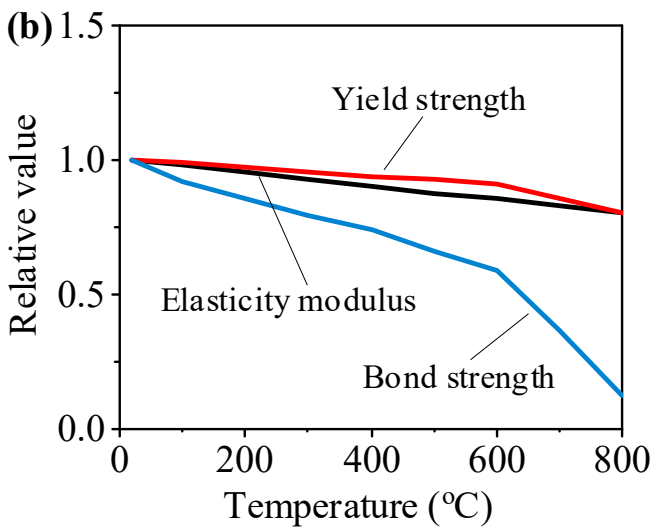

Figure 3. Degradation of mechanical performance after high temperature. (a) Concrete; (b) rebar. 
Table2. Mechanical parameters of concrete components and steel bar at room temperature.

\begin{tabular}{llllll}
\hline Material parameters & Aggregate & Mortar matrix & ITZ & Stirrups & Longitudinal rebars \\
\hline $\begin{array}{l}\text { Compressive strength } f_{\mathrm{c}} \\
(\mathrm{MPa})\end{array}$ & - & 50 & 36 & - & - \\
$\begin{array}{l}\text { Tensile strength } f_{\mathrm{t}}(\mathrm{MPa}) \\
\text { Elastic modulus } E_{\mathrm{c}}\end{array}$ & - & 5.0 & 3.6 & - & - \\
$(\mathrm{GPa})$ & 30 & 32.5 & 30.5 & 200 & 200 \\
Poisson's ratio $v$ & 0.2 & 0.2 & 0.2 & - & - \\
Yield stress $f_{\mathrm{y}}(\mathrm{MPa})$ & - & - & - & 512 & 520 \\
\hline
\end{tabular}

\subsection{Loading and boundary conditions}

ISO 834 curve [20] was adopted to describe the heating regime of $\mathrm{RC}$ short columns in fire accidents. In the analysis of mechanical behavior, a displacementcontrolled loading was employed while the displacement growth rate was $0.4 \mathrm{~mm} / \mathrm{min}$.

\section{Numerical analysis model verification}

The C0 and CR2 specimen in Zhang et al.'s [21] experiment was selected as a reference to verify the numerical simulation model. $\mathrm{C} 0$ is the specimen at room temperature and CR2 is the specimen with initial load after being exposed to fire on four sides. In the simulation, all the dimensions, thermal and mechanical properties of

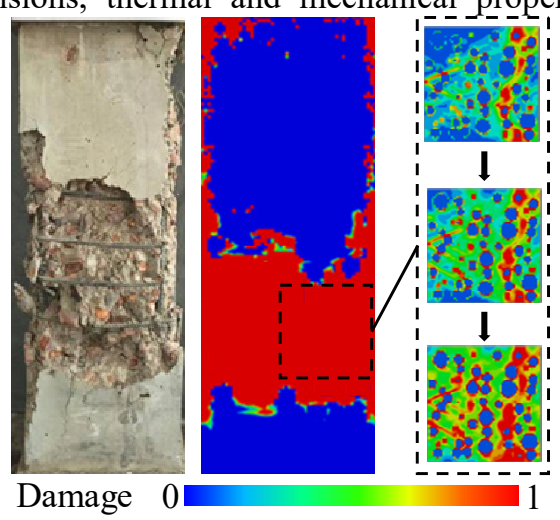

Figure 4. Failure mode of the numerical and experimental [21] at $20^{\circ} \mathrm{C}$.

\section{Parametric studies}

\subsection{Effect of fire scenarios}

The five fire exposure scenarios (namely, fired by single side, opposite two sides, adjacent two sides, three sides, and four sides) with a fire duration of $60 \mathrm{~min}$, the failure mode of RC short column can be noted in figure 6 . The failure mode of short column is axisymmetric under uniform fire. In the case of non-uniform fire, the deterioration of concrete directly exposed to fire is faster than that of concrete subjected to indirect fire. This can be materials as well as boundary and loading conditions were kept as the same as their counterparts in the test.

It can be seen in figure 4 that the failure mode of numerical simulation is similar to that of the test at room temperature. Due to the slip between the longitudinal reinforcement and concrete, the concrete is damaged along the direction of the longitudinal reinforcement cover, which is also consistent with the actual physical test results. Moreover, the concrete failure process can be clearly observed in the mesoscopic model. The cracks first appear within the ITZ phase. Then, the cracks gradually propagated into the mortar matrix, bypassing the aggregates with the load increases, leading to the formation of macro cracks. The load - axial strain curves of the numerical model are in line with the experiment results, as shown in figure 5 .

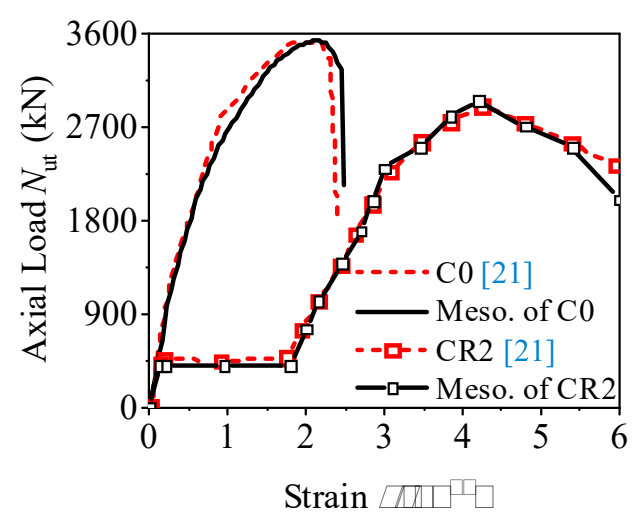

Figure 5. Load $\left(N_{\mathrm{ut}}\right)$ - Axial strain $(\varepsilon)$ curve of RC short columns.

attributed to the fact that the properties of concrete were degraded by the high temperature, generating more serious damage on the fired surfaces.

It can be noted that with the increasing fired surfaces, the falling section of the curve is gentler due to the softening of the concrete materials caused by elevated temperatures, as plotted in figure 7. Moreover, the peak load carrying capacity of the columns on the adjacent two sides decreases more than that of the short columns after exposure to fire on the opposite two sides. This shows that the non-uniform fire makes the bearing capacity of the column further reduced.

A decrease in the axial compression stiffness and ductility coefficient can be easily noticed with the increase 
of the fire surfaces due to the reduced strength and Young's modulus of concrete and steel bars after high temperature, as listed in Table 3. It should be noted that the ductility of the adjacent two sides is less than that of the three sides and four sides. It can be explained by the
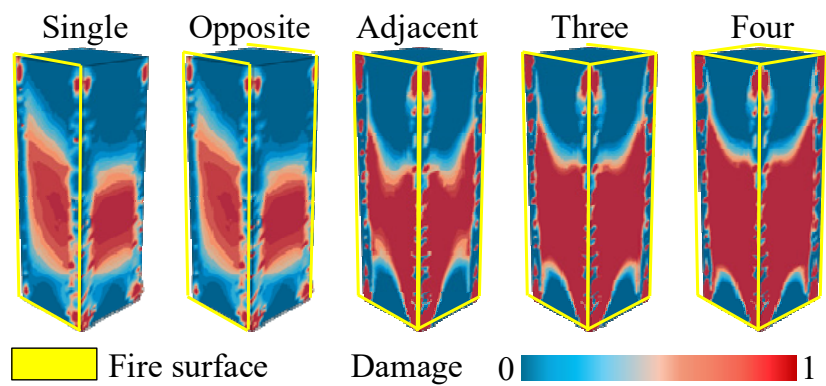

Figure 6. Failure mode of RC short columns after fire for 60 $\min$ at different scenarios. fact that when adjacent two sides of RC short column are exposed to fire, RC short column undergoes eccentric compression under the axial load, dramatically reducing the ductility [3], which further indicates that non-uniform fire has a greater impact on the ductility of columns.

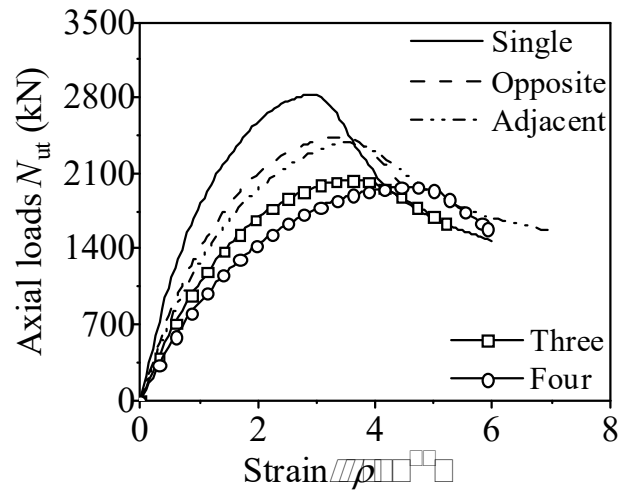

Figure 7. Load $\left(N_{\mathrm{ut}}\right)$-Axial strain $(\varepsilon)$ curve after fire for $60 \mathrm{~min}$ at different fire scenarios.

Table3. Stiffness and ductility at different fire scenarios.

\begin{tabular}{llllll}
\hline Fire surfaces & Single & Opposite & Adjacent & Three & Four \\
\hline Stiffness $E A_{\mathrm{t}}\left(10^{6} \cdot \mathrm{kN}\right)$ & 2.50 & 1.98 & 1.84 & 1.65 & 1.43 \\
Ductility $\mu$ & 1.283 & 1.281 & 1.276 & 1.280 & 1.277 \\
\hline
\end{tabular}

\subsection{Effect of fire duration}

It can be seen in figure 8 that the peak bearing capacity of the side columns decrease gradually with the increase of fire duration. The peak strain of side columns increases with the fire duration, which indicates that the concrete material softens after high temperature. It can be found that the peak bearing capacity shows a nonlinear downward trend as the fire duration increases.

The ratio of stiffness or ductility coefficient after different fire duration to those after $30 \mathrm{~min}$ is used to describe the relationship between fire duration and ductility coefficient or stiffness, as shown in figure 9. The

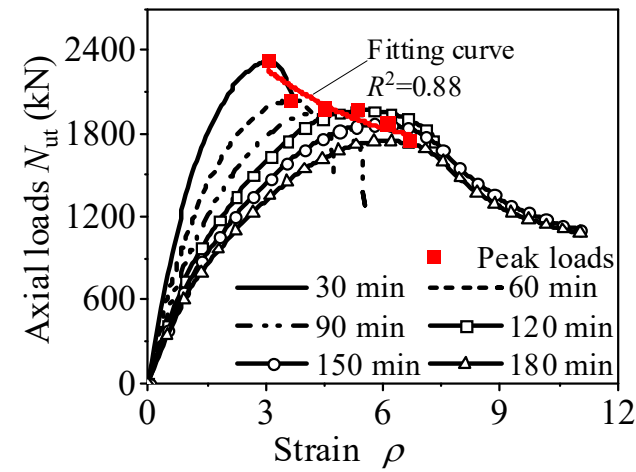

Figure 8. Load $\left(N_{\mathrm{ut}}\right)$-axial strain $(\varepsilon)$ curve of side columns after different durations. ductility coefficient decreases linearly with the increase of fire duration. In addition, it can be noted that for the side columns, the relationship between the axial compression stiffness and the fire duration is a nonlinear function may be adopted to describe this relationship. What's more, the curve is convex to the time axis, indicating the different variation speed of stiffness. This can be attributed to the fact that the axial load of RC short column is mainly borne by concrete. When the time of fire is short (less than 90 $\mathrm{min}$ ), the strength of concrete drops sharply. After $120 \mathrm{~min}$, the maximum temperature of the column section is above $1000{ }^{\circ} \mathrm{C}$, the concrete almost loses all its strength. Consequently, the decreasing trend of axial compression stiffness slows down.

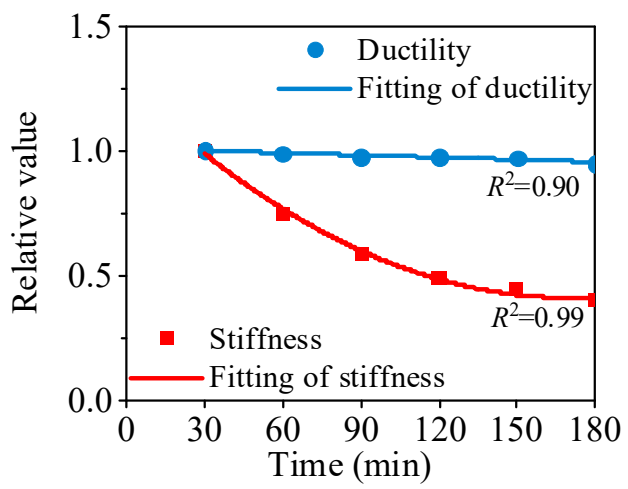

Figure 9. Relationship between the stiffness, ductility and fire durations. 


\section{Conclusions}

In this present work, a 3D mesoscopic numerical model of axial compression of RC short columns after exposure to fire was established. On the basis of the verification of the rationality of the mesoscopic model, the effects of fire scenario and fire duration on the performance of RC short columns under axial load after fire were further discussed. Based on the analysis, the following conclusions can be drawn:

(1) The meso-scale numerical model considering the heterogeneity of concrete can effectively simulate the axial compression performance of RC short columns.

(2) The increase of fire duration and fire surface has adverse effects on the peak bearing capacity, ductility and axial compression stiffness of RC short columns.

(3) After the same fire duration, the non-uniform fire has great influence on the failure mode and the ductility of the column, but has little effect on the axial compression stiffness.

(4) With the increase of fire duration, the peak bearing capacity and stiffness of the side column show a nonlinear downward trend. The relationship between ductility coefficient and fire duration can be described by linear function.

\section{Acknowledgements}

This research was supported by the National Natural Science Foundation of China (No. 51822801, 51978022). The support is gratefully acknowledged.

\section{References:}

1. Abdulraheem M S and Kadhum M M 2018 Experimental investigation of fire effects on ductility and stiffness of reinforced reactive powder $\mathrm{J}$. Build. Eng. 20 750-61

2. Martins A M B and Rodrigues J P C 2010 Fire resistance of reinforced concrete columns with elastically restrained thermal elongation Eng. Struct. $32103330-7$

3. Huo J, Zhang J, Wang Z and Xiao Y 2013 Effects of sustained axial load and cooling phase on post-fire behaviour of reinforced concrete stub columns Fire Safety J. 597 76-87

4. Kodur V K R, Wang T C and Cheng F P 2004 Predicting the fire resistance behavior of high strength concrete columns Cem. Concr. Compos. 26 2 141-53

5. Kodur V and Raut N 2012 A simplified approach for predicting fire resistance of reinforced concrete columns under biaxial bending Eng. Struct. 41 42843

6. Nguyen T T and Tan K H 2014 Thermal-induced restraint forces in reinforced concrete columns subjected to eccentric loads Fire Safety J. 69 136-46

7. Grondin F and Matallah M 2014 How to consider the interfacial transition zones in the finite element modelling of concrete Cem. Concr. Res. 58 67-75

8. Huang Z 2010 Modelling the bond between concrete and reinforcing steel in a fire Eng. Struct. $32 \quad 11$ 3660-9

9. European Committee for Standardization 2004 Eurocode 2: Design of Concrete Structures-Part 12: General Rules-Structural Fire Design (Brussels: Belgium)

10. Khan M I 2002 Factors affecting the thermal properties of concrete and applicability of its prediction models Build. Environ. 376 607-14

11. Vosteen H and Schellschmidt R 2003 Influence of temperature on thermal conductivity, thermal capacity and thermal diffusivity for different types of rock Phys. Chem. Earth. 28 9 499-509

12. Černý R, Maděra J, Poděbradská J, Toman J, Drchalová J, et al. 2000 The effect of compressive stress on thermal and hygric properties of Portland cement mortar in wide temperature and moisture ranges Cem. Concr. Res. 308 1267-76

13. China Association for Engineering Construction Standardization 2006 Technical Code for Fire Safety of Steel Structure in Buildings (Beijing: China Planning Press) (in Chinese)

14. Lubliner L, Ollivier J, Oller S and Onate E 1989 A plastic-damage model for concrete Int. J. Solids Struct. 253 299-326

15. Huang Y, He X, Sun H, Sun Y and Wang Q 2018 Effects of coral, recycled and natural coarse aggregates on the mechanical properties of concrete Constr. Build. Mater. 198 330-47

16. Ministry of Housing and Urban-Rural Development of the People's Republic of China 2010 Code for Design of Concrete Structures (Beijing: China Architecture \& Building Press) (in Chinese)

17. Khaliq W and Taimur 2018 Mechanical and physical response of recycled aggregates high- strength concrete at elevated temperatures Fire Safety J. 96 203-14

18. Wu B 2003 Mechanical properties of reinforced concrete structures after fire (Beijing: Science Press) (in Chinese)

19. Ergün A, Kürklü G and Başpınar M S 2016 The effects of material properties on bond strength between reinforcing bar and concrete exposed to high temperature Constr. Build. Mater. 112 691-8

20. International Organization for Standardization 1999 Fire-Resistance tests-Elements of Building Construction, Part 1: General Requirements (Geneva: Switzerland)

21. Zhang J, Chen J, Huo J, Li S and Cai Z 2017 Experimental study of the effect of fire mode on axial compression mechanical properties of $\mathrm{RC}$ after exposure to entire fire process J Exp. Mech. 1 32 70-8 (in Chinese) 